\title{
LEARNING FROM THE BUILDING: DIRECT SOURCES FOR THE PRESERVATION PROJECT. THE EXPERIENCE OF BESOZZO'S TOWN HALL (VARESE, ITALY)
}

\author{
Susanna BORTOLOTTO ${ }^{1}$, Elisabetta CIOCCHINI ${ }^{1}$, Andrea FRIGO ${ }^{1}$, Andrea \\ GARZULINO $^{1}$, Raffaella SIMONELLI $^{1}$, Fabio ZANGHERI ${ }^{1}$ \\ ${ }^{1}$ Politecnico di Milano, Dipartimento di Progettazione dell'Architettura - DPA, Laboratorio di \\ Diagnostica per la Conservazione e il Riuso del Costruito \\ Via Durando 10, Milano, Italy, susanna.bortolotto@polimi.it
}

Keywords: knowledge, architecture, surveying, stratigraphy analysis, documentation, conservation

\begin{abstract}
The Town Hall of Besozzo (Varese, Italy) is located in the city centre of the village and its first construction phase is dated back to the XIV-XV century. It shows a complex palimpsest which is the result of the numerous transformations occurred during its life: enlargements, super elevations, demolitions, inner spaces subdivisions and use changes. Currently a project has been issued for the reuse of the building which assigns new spaces for the town offices to the northern wing recently acquired. The aim of the research was to provide a diagnostic insight, useful for the development of the conservation project which will necessarily take into account the multitude of values registered on the building. Owing to a lack of meaningful archival documentation, the elevation's stratigraphic reading and the methods for dating historical buildings proved to be an invaluable resource for the comprehension of the building's transformations. Cross-referencing readings of indirect sources carried on the building with the results of the in-depth analysis made it possible to rebuild the growth of the structure from its origin to the present days. Such analysis includes: geometric survey, photographic rectifications of facade and inner sections, non-destructive diagnostic investigations, bricks, mortar and plaster chemical-physical analysis, mensiochronology, study of the building techniques and chronotypology which is a stylistic analysis performed both on the constructive (apertures) and decorative (shelves, graffiti, colourings traces) architectural elements. Blending the results of these dating techniques produced the complexity of the stratigraphic reading which has been conveyed with adequate hatching on the rectified images (U.S. - Stratigraphic Unity) while schematic 3D reconstructions exemplify the chronological sequence of the building activities. Individuation and comprehension of the building constructive phases made also possible to understand which were the different uses of each room inside this domestic architecture thus providing the client and the bodies in charge of protection with valuable data for the preservation project.
\end{abstract}

\section{INTRODUCTION}

Archaeological diagnosis, under good conditions, is a method to discover the physical history of any type of building, based on the materials used in construction (stone and bricks, in the case of the Town Hall of Besozzo), techniques, the 'architectural forms' and the vertical, horizontal and surface stratification. Archaeological reading not as a mandatory practice, but a valuable tool to consider other possible 'points of view', to confirm otherwise 'hypothetical' assessments and to justify further investigations, as well as to rediscover new stability or instability within the building itself. A tool that can draw attention to the 'complexity' of the evolutionary processes of construction, respecting the real physical structures and material components that constitute an unrepeatable specific context, for in-depth knowledge of 'the whole story', in order to optimise specific methods of 'care' and conservation. For the case study of the Town Hall of Besozzo, given the fragmentary nature of the information, it was decided to use dating methods for historical buildings (stratigraphic survey of the elevations, identification of masonry techniques and their chronotypology, mensiochronological analysis of the bricks, the technotypology and chronotypology of the apertures) in order to collect more information and to be able to proceed with a project for conservation and reuse that is aware of the materia signata.

\section{INDIRECT RESEARCH: HISTORICAL AND DOCUMENTARY RESEARCH}

An architectural conservation project presupposes, between the different phases of investigating the building, preliminary historical research in order to clarify the key construction phases of the building, the changes due to different ways of living over time and the maintenance and restoration required to arrest natural and anthropogenic 
degradation. The data resulting from the historical research phase, taken into consideration along with information from other preliminary phases of investigation, helps to define choices for conservation and reuse of the building. The historical analysis of the Town Hall of Besozzo was first set out in the collection of data from local historical publications and subsequently, in research into unpublished archival documents. The tracked down documents, mostly cadastral or notarial in nature, written on behalf of the several families that owned and lived in the grounds of the Town Hall, have allowed the identification of the key phases of construction and more precise dating of some modifications that took place between the fourteenth and twenty-first century, which were also confirmed by direct 'reading' of the building.

\section{GEOMETRIC SURVEY AND PHOTOGRAPHIC RECTIFICATION}

The geometric survey was conducted with a topographic approach to which the necessary detailed surveys were added, and carried out entirely by direct survey. This survey, as well as geometric quantification, also improved the photographic aspect, necessary for the subsequent processing of stratigraphic data. Using data from the topographic campaign led to the realisation of rectified digital photography of the internal frontages of all the places surveyed. This choice turned out to be the most suitable as it allowed any comparison to be made, very quickly, between different parts of the building, maintaining connections between architectural elements, even when belonging to non-adjoining areas. This was an operation that proved useful in the understanding of the architectural works and artefacts and difficult in situ implementation.

\section{DIRECT RESEARCH}

\subsection{Stratigraphic survey of the elevations}

The method of archaeological reading borrowed from real archaeological science provides excellent results in the architectural field as well. This method of application - visual and non-destructive - favours a reading of direct sources, that is, a reading of the information contained on the walls themselves. Furthermore it provides more in-depth knowledge of certain aspects, suggesting from time to time investigation routes that avoid the irreversible loss of authenticity of the building, in full respect for the stratified 'material culture' that has been passed down to us. It is implemented through stratigraphic survey, a type of graphic survey that records the relevant chronologies, recognisable in the constructed parts. The identification of different stratigraphic units (S.U.) and architectural elements (A.E.), along with their exact number, allows us not only to identify every construction activity surveyed, but also to subsequently relate them, until we can draw up the reading by phase (Figure 1). The quality of the results obtained is confirmed by comparison with the stratigraphic data collected and the relevant dating obtained from mensiochronological reading, from analysis of masonry techniques, chronotypology and the results of the historical archival research. The data obtained from the physicochemical characterisation of the materials (bricks and mortar) is also evaluated.

\subsection{Mensiochronology}

The relationship between the measurements of a brick and its period of construction and implementation is now used as a valuable methodological tool for archaeological investigation into construction, in order to verify and support other dating methods of historical construction. It was possible to see how the dimensions of the bricks undergo apparently random and unimportant changes over time depending on region of origin, period of production and different socioeconomic conditions. There were no case studies to refer to for the Besozzo area that could provide useful information about such changes over time. Despite the difficulty in choosing the survey samples, due to the fact that a large part of the building is plastered both internally and externally and that the prevailing construction technique was 'masonry in mixed stone', it was possible to conduct a mensiochronological study with the goal of verifying any differences between stratigraphic units, the quality of the materials used and geometric and technical characteristics. In the case of the Besozzo Town Hall the mensiochronological reading was carried out on the extrados of the vault built between the basement and ground floor and on non-plastered wall surfaces. In this case, the mensiochronological reading was prepared to suppose a relative dating and to verify that the vault could be considered the result of a single construction activity. The barrel vault with lunettes, resulting from the intersection between a barrel vault (set in a rectangular room) and other vaults and made to allow the opening of doorways and windows in the basement, is very thin and is built from reused bricks characterised by reduced thickness and length, no doubt different from those used for the walls. It was then supposed that the creation of the vaulted room could be ascribed to a single phase of construction (seventeenth eighteenth century) which took the pre-existing geometry (position of windows on the south-west façade) into account for the construction of the abutments of the vault and lunettes and which was adapted for the new openings on the north-east façade. It was then possible to date the formation of the doors and windows, whose abutments are characterised by bricks of equal dimension, despite the small number of bricks that could be sampled due to the state of conservation and the presence of traces of plaster. Finally, the chemical-physical analysis of the bricks and mortar 
provided further verification of the quality of the results. This was in order to provide a solid 'foundation' for the formulation of a more aware overall chronological framework of the construction of the architectural palimpsest being studied.
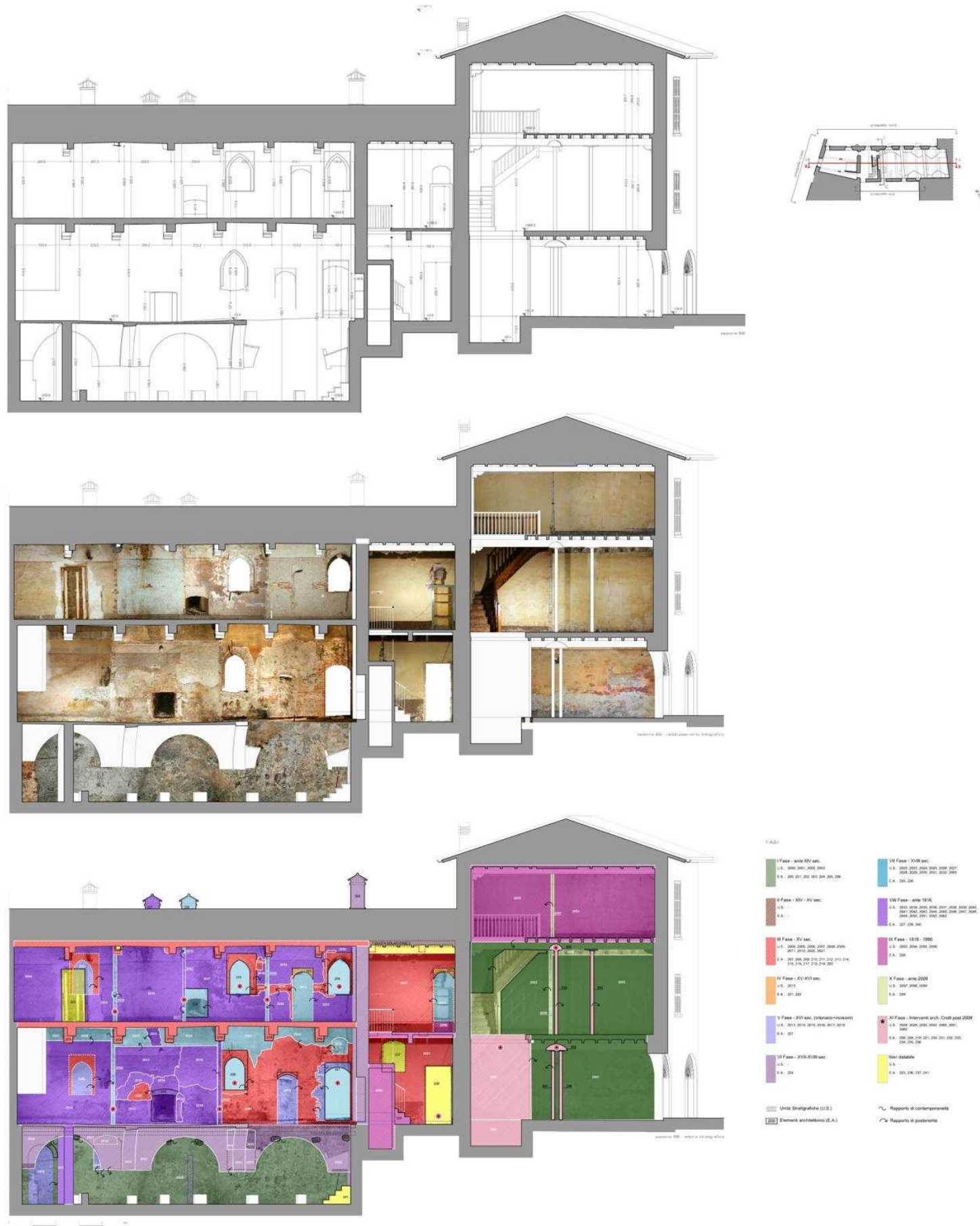

Figure 1: Longitudinal section (BB) - geometric survey, photographic rectification and stratigraphic reading

\subsection{Technotypology and chronotypology of the apertures}

The chronotypology and reading of the masonry techniques or technotypology made it possible to date the historical building relatively. Such direct sources in absence, as is the case at Besozzo, of a local chronotypological curve or catalogue of construction techniques pertaining to the geographical reference, may still be valid interpretations for 
dating the different parts of the architectural structures. Identification of different types of doors and windows and study of different construction techniques allows us to discover record and decode written information on the matter (Figure 2). The files on the doors and windows of the Town Hall of Besozzo include a series of information (size of the perforated patterns, any typological, formal or material differences) derived initially from geometric surveys and photographic rectification of the façades, implemented from data retrieved directly in situ during targeted inspections. Summary files record construction techniques, materials, finishing and information on the presence of shutters, grilles, window shutters, doorsteps, windowsills, railings and their characteristics. All this data was of great use in subsequent readings comparing typological classes and construction activity, as well as chronological readings associated with other analyses performed at the Besozzo Town Hall. As well as supporting the chronology of the architectural structure, the typological analysis of the doors and windows provided information on the way that the internal rooms were used and the role of light within this domestic architecture. Doors and windows with shutters and screens were used for defence, lighting, ventilation and heating. This is more evident to the south, where 'view' windows (lancet windows) and 'light' windows (located on the ground floor, in a high position almost directly below the floor above) can be seen, small openings that allowed the lighting of the entrance halls with the door closed. The support of a 'clothcovered' frame is also supposed, canvas waterproofed with linseed oil, turpentine or something else, reported by indirect (written and iconographic) sources: it should have been a frame positioned in the light towards the exterior, being either fixed or seasonal, or limited to the cold periods of the year. From 'cloth coverings' the system may have moved on to subsequently use leaded glass on a fixed frame, perhaps made of metal, or glass doors mounted on opening doors and windows. As for the doors, on the interior it was necessary to have support for robust metal and wooden doors. On the southern façade two similar filled-in doors on the first floor lead to the hypothesis of the construction (after the construction of the lancet windows) of an external access walkway, dating back to the fifteenth-sixteenth centuries.

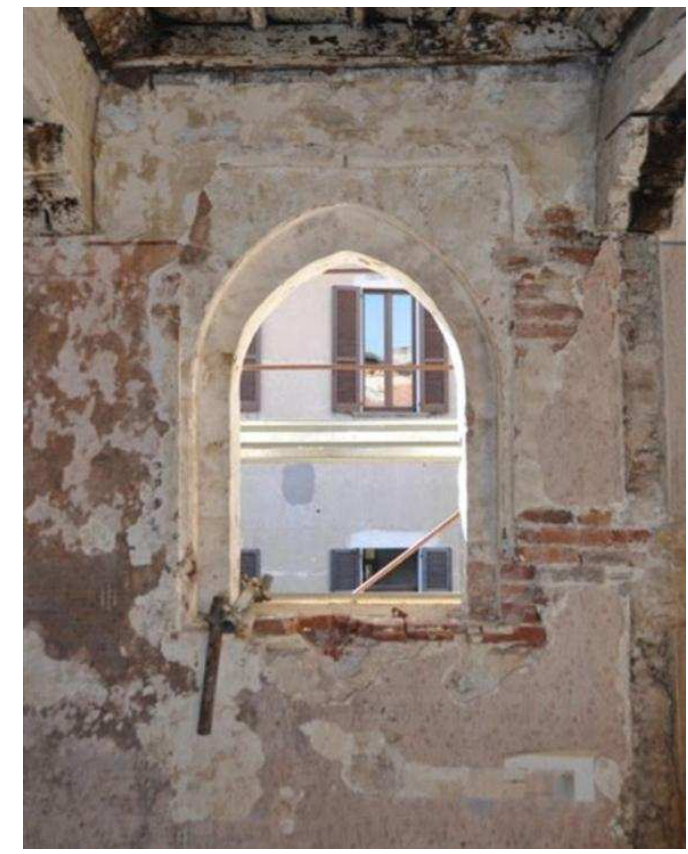

Figure 2: Particular of a ogive window (XIV-XV century) on the south front

\section{CONCLUSIONS: THE CONSTRUCTION PHASES OF THE BUILDING}

The cross-referencing reading with the results ascribable to each survey conducted has allowed us to reconstruct the formation process of the Town Hall of Besozzo. The vast complex is situated in Besozzo (Varese), an important village of ancient origins, site of a castle, home to da Bexutio. The first phases of construction of the complex date back to the early fourteenth century (phase I), and constituted a series of buildings arranged in an L-shape around a courtyard and overlooking in part the village's main road which led west, in part over open spaces situated to the north. Building B, the subject of this study, consisted of a basement room, overlooking the courtyard, perhaps destined for use as a cellar 
or storeroom, covered with a wooden floor slab supported by stone corbels. Between the fourteenth and fifteenth century (phase II) the room, destined for new use as accommodation or a service room, underwent a first modification with the opening of two large windows on the southern façade and the reconstruction of the floor, placed at a higher altitude. During the fifteenth century (phase III) the building was radically transformed with the addition of two floors, in conjunction with the partial expansion of the courtyard. The two large new rooms, located on the ground and first floors, were covered with wooden slabs supported by wooden brackets. The building was accessed through a small, low-vaulted door on the first floor. The new rooms were illuminated by five large lancet windows, three of which still exist. The shape of the windows, doors and wooden brackets (Figure 3) allow us to date with some confidence the new construction to throughout the fifteenth century, although both the building traditions consolidated among local workers and the distance from Milan and Pavia, the major cultural centres of the Duchy of Milan, may postpone the date to within the first two decades of the sixteenth century. Between the fifteenth and sixteenth century (phase IV), probable internal divisions made on the first floor called for the opening of two doors on the southern facade, reached by an access ladder to a wooden walkway, which no longer exists. During the sixteenth century (phase V) the level of the internal courtyard was probably raised, permanently reducing the space below, built during the first construction phase, to a cellar or storeroom. It is during this phase that the apertures of the space were filled in and the construction of the body of building $\mathrm{D}$ on the east side of the court took place. The change in the level of the floor of the court involved a series of changes: raising the ceiling of the ground floor, the walling-in of the old access and the opening in breach of a new entrance, of similar shape but larger in size. The coeval opening of a 'light window' above the new access door allowed for the hypothesis of a closing system with locks made of wooden support boards for the lancet 'view' windows. The entire southern façade was plastered and perhaps painted later, as proved by traces of blue and red and engraving with geometric patterns (Figure 4).

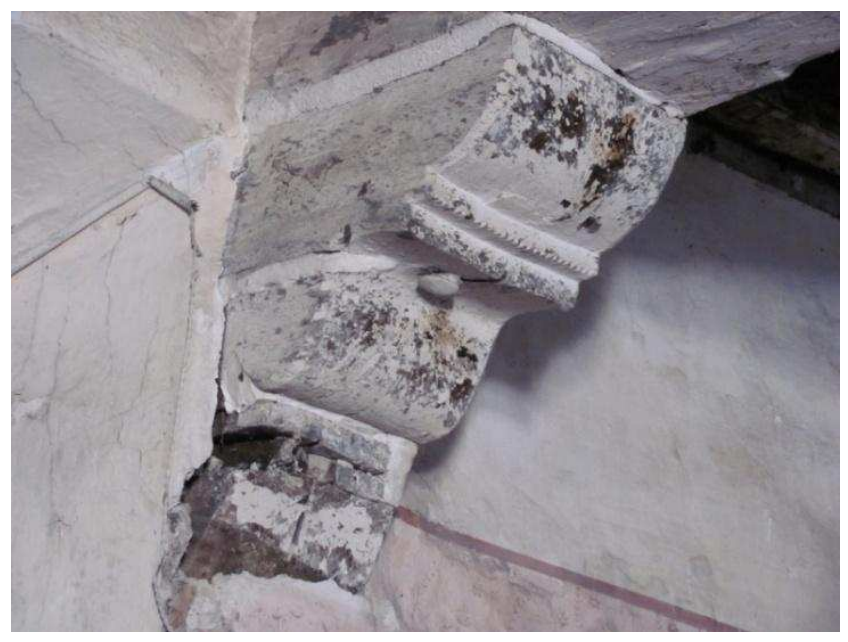

Figure 3: A wooden bracket of XV-XVI century.

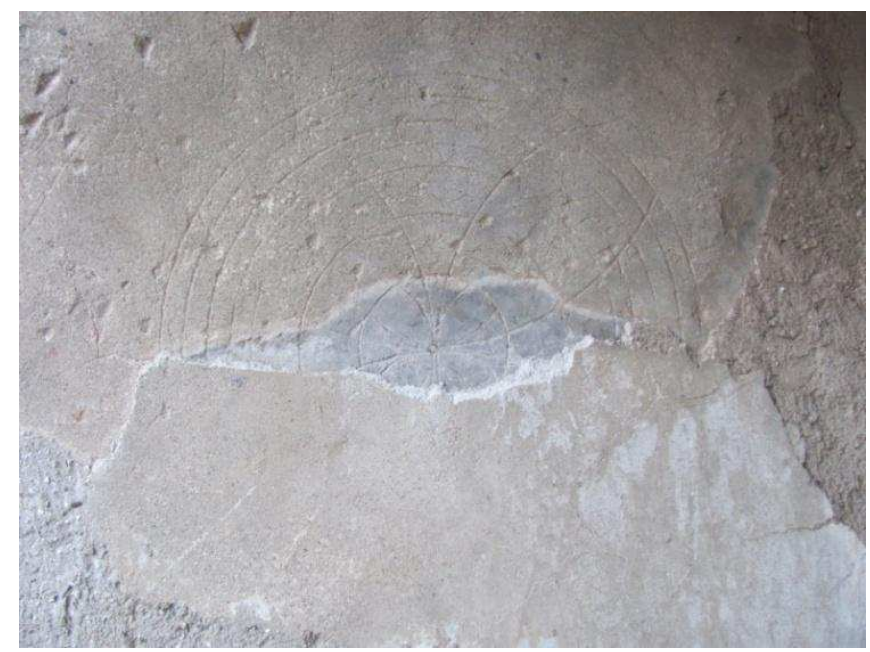

Figure 4: Particular of geometric patterns in the ancient plaster. 


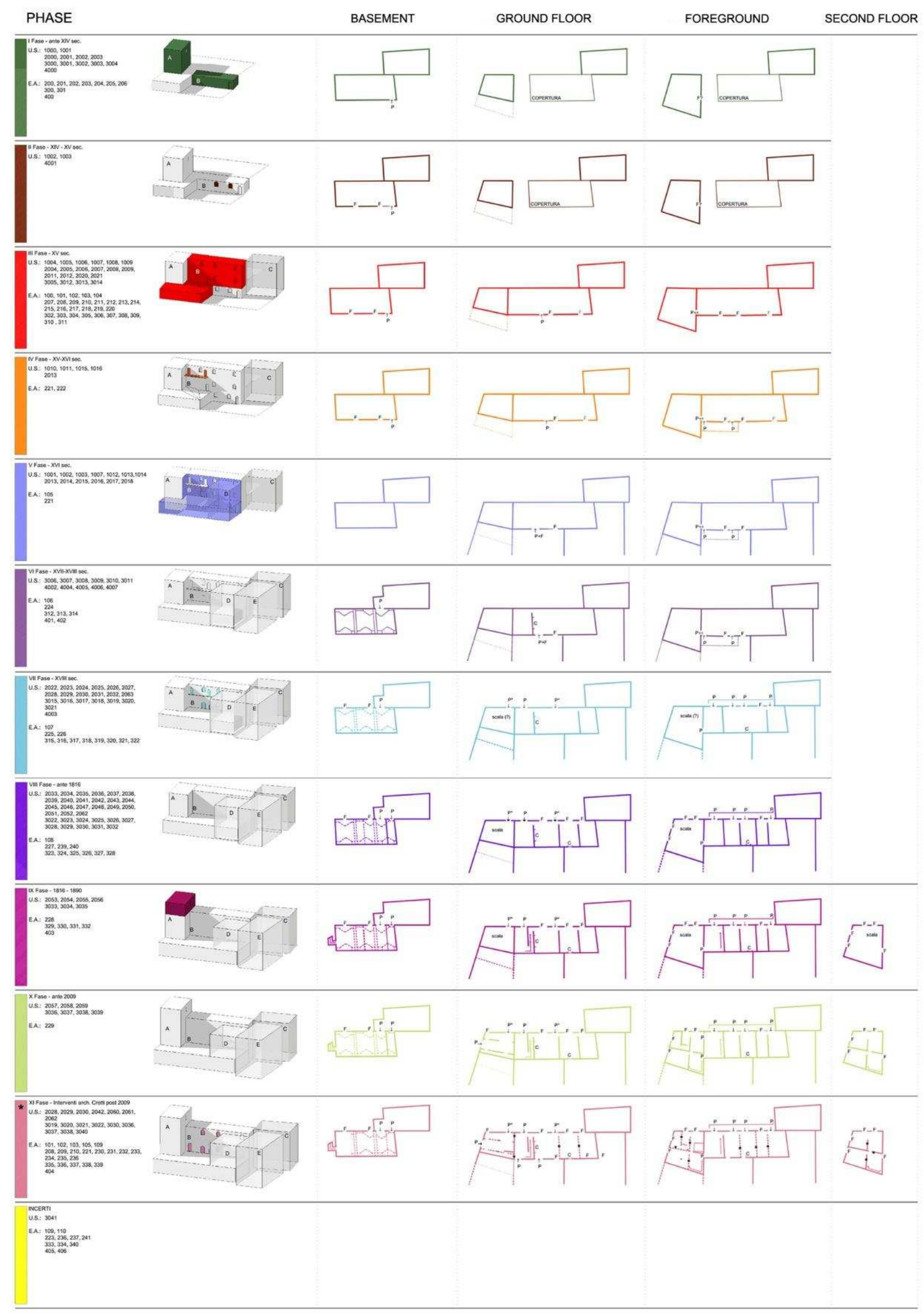

Figure 5: Schematic representation of the building's historical evolution on the different levels. 
Between the seventeenth and eighteenth century (phase VI) the building passed hands from the Castelbesozzi to the Masnaghi family and was transformed into a genuine 'nobleman's home'. The ground floor room was decorated with a large framed fireplace, perhaps in Macchiavecchia, removed after 2005. During the eighteenth century (phase VII) the Masnaghi family filled in all the existing apertures on the southern façade of the building and opened doors and windows to the north. To the end of the eighteenth century the building, under the new ownership of Mazzola and Del Vitto, was home to a workshop and was internally divided, on the first and ground floors, into rooms to rent, to which access was provided by a stone walkway. By 1816 (phase VIII) further internal adaptations were made and, between 1816 and 1890 (phase IX), the complex was expanded by the construction, in the northwest corner of the courtyard overlooking the street, of a space used as shop/restaurant with an upper room and a porch with a shed, barn and hayloft above, pulled down in the late twentieth century. Until the sixties (phase X) the building remained in the hands of Del Vitto with no further modifications. In 2006 it was sold to the Town of Besozzo and between 2009 and 2011 studies and initial restoration work began (Figure 5). The reconstruction of the formation process of the building by its construction phases is closely tied to the concept of a layered palimpsest, understood as the unique, irreproducible deposit of material culture that will guide the future project of conservation and reuse. With respect to all of the analyses carried out such a project will therefore be more attentive to the differences than to similarities and claim awareness of the singularity, specificity and irreproducibility of every sign of time and man, read on the materia signata.

\section{REFERENCES}

[1] Brunella, R.L.: Frammenti di storia besozzese. Brevi notizie preistoriche e storiche di Besozzo e dintorni, Besozzo, 1960 .

[2] Boriani, M.(a cura di): Patrimonio archeologico, progetto architettonico e urbano, Firenze, 1997.

[3] Bortolotto, S.: Il rilievo stratigrafico, in C. Campanella (a cura di) "Il rilievo degli edifici", Milano, 2004, pp.94115 .

[4] Bortolotto, S., Colla, C., Mirandola, D., Sponchioni, A.: Palazzo Cittadini Stampa: role of stratigraphy and cinematic analysys in the knowledge of a mansonry building, C. Modena, P.B. Lourenco, P. Roca (a cura di), Structural analysis of historical constructions. Possibilities of numerical and experimental techniques, London, 2005, 1, 167-175.

[5] Bortolotto, S., Campanella, C., Tessoni, M., Macchi, A.: Methods for dating historical buildings and verticality control of the Baronale Palace at Avio's Castle (TN), CIPA: "International cooperation to save the world's cultural heritage", Torino, settembre 2005, 177-182.

[6] Parenti, R.: Sulle possibilità di datazione e di classificazione delle murature, in R. Francovich, R. Parenti (a cura di), Archeologia e restauro dei monumenti, Firenze, 1988, 280-304.

[7] Gabrielli, F.: La "cronotipologia relativa" come metodo di analisi degli elevati: la facciata del Palazzo Pubblico di Siena, Archeologia dell'Architettura", I, 1996, 17-40.

[8] Mannoni, T., Milanese, M.: Mensiocronologia, in R. Francovich, R. Parenti (a cura di), Archeologia e restauro dei monumenti, Firenze, 1988, 383-402. 